\title{
QUALIDADE DE TUBÉRCULOS DE BATATAS -SEMENTE TRATADOS COM PARAQUAT E O DESENVOLVIMENTO DE UMA METODOLOGIA SIMPLIFICADA DE DETECÇÃO DE RESÍDUO DO HERBICIDA ${ }^{1}$
}

\author{
WELINGTON PEREIRA ${ }^{2}$ e RAQUEL L. DANTAS ${ }^{3}$
}

\begin{abstract}
RESUMO
O objetivo desse trabalho foi avaliar a qualidade de tubérculos de batatas-semente (Solanum tuberosum) tratados com paraquat e desenvolver uma metodologia simplificada de detecção de resíduos do herbicida. Dois ensaios foram realizados no Laboratório da Ciência das Plantas Daninhas do Centro Nacional de Pesquisa de Hortaliças, Brasília, DF. No primeiro experimento, tubérculos das cultivares Achat e Baronesa foram submersos em soluções de 0 e 200 ppm de paraquat ou injetados com $0,5 \mathrm{ml}$ de soluções de 0 e 200 ppm do herbicida. $\mathrm{O}$ delineamento experimental foi inteiramente casualizado com 8 repetições e 12 tubérculos por parcela. Os tubérculos foram colocados em câmara fria, após a aplicação com paraquat, para quebra da dormência. Após a brotação dos tubérculos avaliou-se a qualidade interna dos mesmos, amostrando, posteriormente, 2 tubérculos de cada parcela para o plantio em vasos, sob condições de telado, para verificar possíveis danos no crescimento das plantas oriundas dos tubérculos tratados. Os tratamentos de imersão não provocaram, aparentemente, nenhum dano intemo nos tubérculos, ou nem mesmo afetaram a nova geração, entretanto, os tubérculos injetados com paraquat foram severamente deteriorados e carbonizados, originando plantas bastante debilitadas. Esses resultados indicam que quando o paraquat for aplicado sob condições que favoreçam sua penetração ou translocação para o interior do tubérculo, atingindo os vasos e a polpa, pode danificá-lo severamente, prejudicar sua apa-

rência, qualidade de produção e reduzir o desenvolvimento da nova geração de plantas oriundas dos tubérculos contaminados. No segundo experimento, desenvolveu-se uma metodologia simplificada para detectar resíduos de paraquat nos tubérculos através de colorimetria, visto que o paraquat é reduzido a um radical de cor azul na presença de ditionito de sódio (Na2S2O4) a $1 \%$ em meio básico, a qual se intensifica à medida que a concentração do produto aumenta. A metodologia simplificada desenvolvida permitiu detectar resíduos de paraquat ao nível de $0,06 \mathrm{ppm}$, indicando uma excelente aproximação, pois, o limite de tolerância do paraquat em tubérculos de batata é de $0,2 \mathrm{ppm}$, normalmente, determinado pelo método analítico completo, que apresenta limites de detecção em torno de 0,01 ppm e recuperação acima de $70 \%$. Uma avaliação qualitativa da concentração residual do produto nas amostras foi possível através de leituras e comparações visuais entre os diferentes graus de cores desenvolvidas nas soluções padrão e a cor desenvolvida na amostra, não necessitando, portanto, das leituras colorimétricas, podendo ser feita inclusive no campo. Observou-se que a maioria do paraquat pemaneceu na região da casca até o período de 4 semanas após a aplicação do paraquat.

Palavras-chave: Colorimetria, método de análise, ditionito de sódio, Solanum tuberosum, dessecação, sobrevivência, produtividade.
\end{abstract}

\section{ABSTRACT \\ Quality of seed potato tubers treated with paraquat and the development of a simplified methodology for paraquat residue detection}

Seed potatoes tubers (Solanum tuberosum) of two cultivais (Achat and Baronesa) were treated with paraquat solu tions to evaluate the intemal tuber quality and to detect its residue by a simplified methodology. Two experiments were

1 Recebido para publicação em 20/11/94 e na forma revisada em 05.06/95.

2 Eng $^{\circ}$ Agr $^{\circ}$, PhD, Centro Nacional de Pesquisa de Hortaliças / EMBRAPA, Caixa Postal 218, Brasilia, DF 70359-970

3 Estudante de Agronomia, Bolsista do CNPq, Departamento de Eng. Agronômica, Universidade de Brasilia, Caixa Postal 04.508, Brasilia, DF 70910-970 
carried out at the National Research Center on Vegetables, Brasilia, DF. In experiment one some tubers were immersed in 0 and $200 \mathrm{ppm}$ of paraquat solutions and others were injected with $0.5 \mathrm{ml}$ of 0 and $200 \mathrm{ppm}$ solutions of the herbicide. Twelve tubers were used as a plot in a complete randomized design with 8 replications. The internal tuber quality was evaluated after breaking dormancy and sprouting of ten tubers. Also, two tubers were sampled and put in 5 liter pots and grown under greenhouse conditions to observe if the herbicide would affect the growth of the new plant generation. The immersion treatments did not cause any internal damage to the tubers nor did they affect the new plant generation; however, tubers injected with paraquat were severely damaged (carbonization). Also, the next plant generation was affected and the surviving plants were small and not vigorous. These results indicate that paraquat can severely damage those tubers that had absorbed and/or translocated the herbicide. In experiment two a simplified methodology

\section{INTRODUÇÃO}

Um dos fatores ]imitantes na produção de batatassemente é a manutenção da sanidade e qualidade fisiológica e fitossanitária das plantas até o final do ciclo (Book, 1975 e 1976; Haderlie et. al., 1989; Pereira, 1987b). Para diminuir, portanto, a contaminação por vírus, evitar o ataque tardio de fungos, prevenir o aparecimento de podridões nos tubérculos, pratica-se, normalmente, a dessecação antecipada da parte aérea das plantas com o uso de dessecantes químicos. Esta prática, além de garantir maior sanidade dos tubérculos, permite maior uniformidade dos mesmos e maior aderência da película, resultando em melhor conservação e aceitação do produto.

Os produtos registrados no Ministério da Agricultura, do Abastecimentto e da Reforma Agrária e empregados pelos produtores como dessecantes na produção de batatasemente têm sido, normalmente, o paraquat e diquat (Andrei, 1993, Pereira, 1987a), os quais são herbicidas não seletivos, com ação de contato, do grupo dos bipiridilios (WSSA, 1983). Eles são absorvidos rapidamente nas folhas, não sendo, normalmente, removidos pela água da chuva ou de irrigação após 30 minutos da aplicação; não são absorvidos pelas raízes, pois, ficam adsorvidos pelas argilas quando em contato com o solo. Em condições normais são muito pouco translocados no interior da planta (Klingman \& Ashton, 1975); entretanto, tem sido relatado que eles podem apresentar alguma ação sistémica local, com pequena translocação via xilema, sob certas condições ambientais, como: longo período sem luz após a aplicação do produto (Souza \& Bonin, 1983, 1988) e quando aplicado em condições de déficit hídrico. Souza e Bonin (1988) e Souza (1990) sugeriram que se deve evitar a aplicação de dessecantes em período de estiagem (seca), e também recomendaram a aplicação do paraquat no período da manhã, para que o produto possa ser ativado imediatamente após a sua aplicação, diminuindo as possibilidades da pequena translocação do mesmo. Relatos informais de técnicos e produtores de batatas-semente têm demonstrado que o produto pode promover danos aos tubér to detect paraquat residue in the tubers was set up by colorimetric means. Paraquat was reduced with sodium dithionite $\left(\mathrm{Na}_{2} \mathrm{~S}_{2} \mathrm{O}_{4}\right)$ in basic solution to a blue radical ion which intensified its color with any increase in paraquat concentration. The development of this simplified methodology allowed the detection of paraquat residue above 0,06 ppm, indicating an excellent sensitivity and recovery in comparison with the residue analytical procedure of this herbicide, with a limit of detectability of about 0,01 ppm in crop samples of $200 \mathrm{~g}$. In addition to the quantitative determination of paraquat, this methodology allows to determine qualitatively paraquat concentration by colour comparisons. Most of the paraquat residue was determined from potato skins up to 4 weeks after paraquat application.

Additional index words: Colorimetry, method of analysis, sodium dithionite, Solanum tuberosum, survival, productivity.

culos, como: escurecimento na região de inserção do caule ou na polpa da batata e anomalias no crescimento das plantas na geração posterior; chegando algumas vezes a comprometer em demasia a qualidade dos tubérculos e a economia da produção de batatas-semente.

Segundo as normas estabelecidas pelos Ministérios da Saúde e da Agricultura, do Abastecimento e da Reforma Agrária o uso do paraquat requer um intervalo de segurança de 7 dias após a sua aplicação, com tolerância máxima de resíduo de 0,2 ppm (Andrei, 1993). Sendo assim, além das possibilidades do paraquat danificar os tubérculos, comprometendo a produção, seu uso exige cuidado e supervisão, por se tratar de um produto altamente tóxico (classe toxicológica I), não se recomendando usá-lo na cultura de batata para consumo, para se evitar possível ingestão de tubérculos com resíduo do herbicida.

O método analítico, tido como clássico, de análise do paraquat (Zweig, 1967) requer o uso de corrida das amostras em colunas de resinas para captura das suas moléculas. É um método geralmente caro e demorado, necessitando de equipamentos especiais.

O objetivo deste trabalho foi avaliar a qualidadde de tubérculos de batatas-semente tratados com paraquat, observando seus efeitos sobre a aparência, conservação, brotação e características de crescimento da nova geração de plantas; e desenvolver uma metodologia simplificada de detecção de resíduos do herbicida.

\section{MATERIAL E MÉTODOS}

\section{Ação do paraquat sobre os tubérculos.}

Os experimentos foram conduzidos no Laboratório da Ciência das Plantas Daninhas do Centro Nacional de Pesquisa de Hortaliças / EMBRAPA, Brasilia, DF. Foram utilizados tubérculos de batata das cultivares Achat e Baronesa, colhidas de campos experimentais do Centro.

$\mathrm{O}$ trabalho constou basicamente de duas etapas. $\mathrm{Na}$ primeira os tubérculos foram tratados com paraquat, e arma- 
zenados em cámara fria para quebra da dormência. Na segunda etapa foi avaliada a sobrevivência e características de crescimento dos tubérculos e das plantas da nova geração. Inicialmente os tubérculos foram padronizados de acordo com o tamanho, observando-se a integridade da película. Utilizou-se 12 tubérculos por parcela, em um delineamento inteiramente casualizado, com 8 repetições em um arranjo fatorial $2 \times 2 \times 2$. Os tratamentos constaram de dois genotipos ('Achat' e 'Baronesa'), dois modos de aplicação e duas doses (imersão por 10 minutos das batatas em soluções de 0 e 200 ppm de paraquat e injeção de $0,5 \mathrm{ml}$ de soluções de 0 e 200 ppm de paraquat, usando-se uma seringa plástica.

Após a aplicação dos tratamentos, os tubérculos foram deixados à sombra para secagem, sendo acondicionados em sacos de papel e colocados em câmara fria a $5 \pm 1{ }^{\circ} \mathrm{C}$, para a quebra da dormência. Após 2 meses, os tubérculos foram retirados e deixados nos sacos de papel por mais 45 dias em local arejado e sob luz difusa, para estimular a brotação. Após este período, os tubérculos foram pesados novamente, avaliando a perda de peso ocorrida em cada tratamento. A aparência externa e a brotação dos tubérculos tratados foram avaliadas em relação à dose zero, em cada cultivar e modo de aplicação. Por outro lado, os danos internos foram avaliados através de cortes transversais e longitudinais nos tubérculos, atribuindo notas de 0 a 100 para a aparência interna, correspondentes a percentagens de danos $(0 \%=$ sem dano e $100 \%$ $=$ total deterioração). Os dados foram transformados em arc senx, para efeito da análise estatística.

Para a avaliação da sobrevivência e características de crescimento da geração seguinte, amostraram-se, aleatoriamente, dois tubérculos de cada parcela para o plantio individual em vasos preenchido com uma mistura de solo areno argiloso, tratado com brometo de metila, mantendo-os sob condições de telado, com irrigação diária, e adubação nitrogenada das plantas, em cobertura, aos 15 e 30 dias. As plantas foram tutoradas através de estaqueamento e amarração.

Aos 50 dias foram contadas as hastes por planta e colhidas as plantas, avaliando-se as características de crescimento e o potencial de tuberização, através dos seguintes parâmetros: 1) peso da matéria seca da parte aérea; 2) número de tubérculos por planta e 3) peso dos tubérculos por planta.

\section{Metodologia simplificada para detecção de resíduo de paraquatem batata.}

O desenvolvimento desta metodologia foi baseado no princípio da redução da molécula de paraquat pelo ditionito de sódio $\left(\mathrm{Na}_{2} \mathrm{~S}_{2} \mathrm{O}_{4}\right) \quad 1 \%$ em meio básico de hidróxido de sódio $0,1 \mathrm{~N}$, que produz um radical de cor azul, que se intensifica à medida que a concentração do produto aumenta, permitindo, portanto, sua determinação pelo método da colorimetria. Os experimentos para o estabelecimento da metodologia constaram de 3 etapas: 2.1. preparo da curva padrão do paraquat; 2.2. simulação do resíduo através de imersão de amostras de tubérculos de batata cv. Achat em diferentes concentrações de paraquat e 23. análise do resíduo nas amostras.
Inicialmente, as análises de resíduo simulado foram feitas logo após a aplicação do paraquat nos tubérculos, usando 7 concentrações do produto em amostras de $100 \mathrm{~g}$ de batata, repetidas 7 vezes. Posteriormente, variou-se de 1 a 4 semanas o período entre a aplicação do herbicida e as análises; repetindo-se 3 vezes cada tratamento, em um delineamento inteiramente casualizado, com a finalidade de avaliar possíveis alterações na concentração do resíduo no tempo, após a aplicação do paraquat.

\subsection{Curva padrão do paraquat.}

Preparou-se uma solução de paraquat em água, 0,02 $\mathrm{mg} / \mathrm{ml}$ (solução 1). Desta solução transferiu-se $10 \mathrm{ml}$ para um balão volumétrico de $500 \mathrm{ml}$ e completou-se o volume com água, 0,4 mg/1 (solução 2), e transferindo $5 \mathrm{ml}$ deste para um volume final de $250 \mathrm{ml}$, obteve-se $0,008 \mathrm{mg} / 1$ (solução 3). Pipetou-se, posteriormente, $10 \mathrm{ml}$ das soluções 2 e 3 e alíquotas de 1, 2, 4, 6, 8 e $10 \mathrm{ml}$ da solução 1, equivalendo a 8 amostras de 0,00008, 0,004, 0,02, 0,04, 0,08, 0,12, 0,16 e $0,2 \mathrm{mg}$ de paraquat. Diluiu-se estas amostras com aproximadamente $80 \mathrm{ml}$ de água e adicionou-se $10 \mathrm{ml}$ de solução de ditionito de sódio $1 \%$ em NaOH $0,1 \mathrm{~N}$ em cada balão, completando o volume com água até $100 \mathrm{ml}$. Por ser instável, a solução de ditionito de sódio foi usada no período de até tres horas após o preparo, de acordo com recomendação de Zweig (1967). Os frascos com as amostras devem ser vedados à luz e as soluções misturadas levemente, com cuidado, para evitar a oxidação com o ar e a diminuição da cor. As leituras colorimétricas foram feitas em um espectrofotômetro (Micronal B295) em 600 nm, usando a solução de 0,008 $\mathrm{mg} / 1$ como branco para calibrar o aparelho. Os valores lidos em transmitáncia $(\mathrm{T})$ foram transformados em absorbáncia $(\mathrm{A}=\log 1 / 1)$ e a partir daí foi preparada a curva padrão em relação a concentração do paraquat (Figura 1).

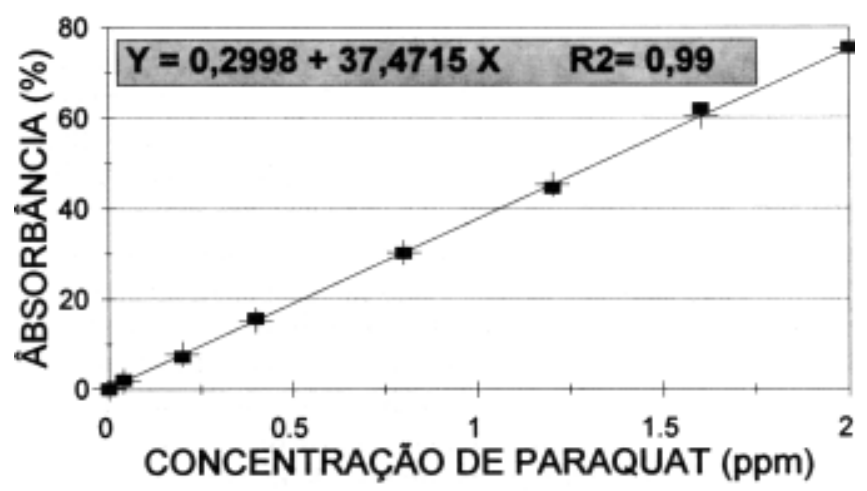

FIG. 1 - Curva padrão do paraquat para detecção de resíduos em batata (+ = regressão: $\mathbf{y}=\mathbf{0 , 2 9 9 8 +}$ $37,4715 x$, onde $y=$ absorbância em $\%$ e $x=$ concentraçáo do paraquat em ppm), e os valores observados ( $=$ amostras padráo).

\subsection{Simulação do resíduo de paraquat nos tubércu-} los de batata.

Em testes preliminares foi observado que $100 \mathrm{~g}$ de batatas imersas por 10 minutos em $200 \mathrm{ml}$ de solução retiveram, aproximadamente, $2 \mathrm{ml}$ do volume inicial da solução. Partindo deste resultado, vários níveis de resíduo foram 
simulados para constatar a eficiência do método simplificado.

Posteriormente, as amostras de $100 \mathrm{~g}$ de tubérculos de batata foram submersas, por 10 minutos, em $200 \mathrm{ml}$ das seguintes soluções de paraquat : $0,04,1,3,5,7,10$ e $20 \mathrm{ppm}$ Dessa forma, teoricamente as amostras foram contaminadas com os seguintes níveis de resíduo: $0,0008,0,02,0,06,0,10$, $0,14,0,20$ e 0,40 ppm de paraquat.

\subsection{Análise do resíduo de paraquat nas amostras.}

Trinta minutos após a aplicação das doses de paraquat, os tubérculos de cada amostra foram descascados uniformemente, pesando-se as cascas e, posteriormente, recortandoas, em pequenos pedaços, para aumentar a superficie de exposição.

Cada amostra de cascas foi colocada em um bequer de $500 \mathrm{ml}$ e submersa em $50 \mathrm{ml}$ de água, agitando-se com um bastão de vidro por dez segundos. Rapidamente adicionou-se $50 \mathrm{ml}$ de ditionito de sódio $1 \%$ em $\mathrm{NaOH} 0,1 \mathrm{~N}$ e misturouse levemente para completar o aparecimento da cor e, com o auxílio de uma peneira fina e um funil transferiu-se as soluções para balões volumétricos de $100 \mathrm{ml}$, que foram então vedados da luz. Devido à instabilidade da cor desenvolvida, as leituras foram feitas no espectrofotômetro $(600 \mathrm{~nm})$, num intervalo de até 10 minutos após a mistura, a partir do qual a cor tende a perder suas características originais.

Os resultados obtidos em transmitância foram transformados em absorbáncia e, posteriormente, interpolados na curva padrão, estimando a concentração de resíduo através da equação ajustada $\mathrm{Y}=0,299849+37,47154 \mathrm{X}$, onde $\mathrm{Y}=$ absorbáncia em \% e X = concentração de paraquat em ppm (Figura 1).

Os mesmos procedimentos foram adotados para as análises realizadas de 1 a 4 semanas após a aplicação do herbicida.

\section{RESULTADOS E DISCUSSÃO}

\section{1) Ação do paraquat sobre os tubérculos de batata.}

$\mathrm{Na}$ avaliação da qualidade externa e interna dos tubérculos observou-se diferenças significativas nos tratamentos de injeção com paraquat (Tabela 1). Os tratamentos de imersão não promoveram aparentemente nenhum dano aos tubérculos, comparados à dose zero. Nos tubérculos injetados com água, observou-se pequenas manchas necróticas internamente, limitadas, entretanto, à região onde foi introduzida a agulha, representando até $4,1 \%$ do volume do tubérculo. Os tubérculos injetados com paraquat, apresentaram um escurecimento externo com deformação pronunciada da casca (enrugamento) e internamente, escurecimento da polpa, com necroses, formando cavidades e alterações do tecido da polpa (carbonização), danificando de 58 a $85 \%$ do volume total do tubérculo (Tabela 1). O paraquat danificou mais a cultivar Achat do que a Baronesa, provavelmente, devido ao maior conteúdo de água apresentado pela primeira cultivar, a qual interfere, significativamente, na reação do paraquat. $\mathrm{O}$ paraquat injetado nos tubérculos reduziu significativamente o peso fresco das batatas, comprometendo a conservação dos tubérculos (Tabela 1).

Os tubérculos das cultivares Achat e Baronesa imersos nas soluções de paraquat apresentaram brotação aparentemente normal, bastante vigorosa e uniforme. Por outro lado, os tubérculos da "Achat" injetados com paraquat apresentaram brotação anormal, emitindo pequenos tubérculos nos locais das gemas, indicando alguma forma de sobrevivência devido ao esgotamento das reservas dos tubérculos, causado pelos danos internos pelo paraquat. Os tubérculos da "Baronesa" apesar de danificados apresentaram brotação aparentemente normal (Tabela 2).

TABELA 1 - Resultados médios do dano interno (\%) e perda de peso $(\mathrm{g})$ dos tubérculos, após a quebra de dormência e brotação de duas cultivares de batata tratados com paraquat.

\begin{tabular}{|c|c|c|c|c|}
\hline Cultivar & Modo de aplicaçäo & $\begin{array}{c}\text { Concentração de } \\
\text { paraquat (ppm) }\end{array}$ & $\begin{array}{l}\text { Dano interno no } \\
\text { tubérculo }(\%)\end{array}$ & $\begin{array}{l}\text { Perda de peso dos } \\
\text { tubérculos }{ }^{*}(\mathrm{~g})\end{array}$ \\
\hline \multirow[t]{2}{*}{ Achat } & Imersão & 0 & 0,0 & 5,9 \\
\hline & & 200 & 0,0 & 6,4 \\
\hline \multirow[t]{2}{*}{ Achat } & Injeção & 0 & 3,0 & 8,5 \\
\hline & & 200 & 84,8 & 20,9 \\
\hline \multirow[t]{2}{*}{ Baronesa } & Imersão & 0 & 0,0 & 6,6 \\
\hline & & 200 & 0,0 & 8,3 \\
\hline \multirow[t]{2}{*}{ Baronesa } & Injeção & 0 & 4,1 & 8,8 \\
\hline & & 200 & 58,1 & 20,0 \\
\hline DMS (5\%) & - & - & 5,3 & 1,7 \\
\hline
\end{tabular}

* Interaçáo cultivar*modo de aplicaçāo*dose, significativa pelo teste $\mathrm{F}$ a $1 \%$ de probabilidade. Os dados foram transformados $\mathrm{em}$ arc sen $\sqrt{\% / 100}$, para efeito da análise estatística.

** Interaçáo modo de aplicaçăo*dose significativa pelo teste $\mathrm{F}$ a $1 \%$ de probabilidade.

Planta Daninha, v. 13, n. 1, 1995. 
TABELA 2 - Resultados médios do número de hastes por planta, peso da matéria seca da parte aérea (g) por planta, número de tubérculos por planta e peso dos tubérculos produzidos $(\mathrm{g})$ por planta aos 50 dias após o plantio dos tubérculos de duas cultivares de batata tratados com paraquat.

\begin{tabular}{|c|c|c|c|c|c|c|}
\hline Cultivar & $\begin{array}{l}\text { Modo de } \\
\text { aplicação }\end{array}$ & $\begin{array}{c}\text { Dose de } \\
\text { paraquat } \\
\text { (ppm) }\end{array}$ & $\begin{array}{l}\text { Número de } \\
\text { hastes }\end{array}$ & $\begin{array}{c}\text { Peso da } \\
\text { matéria seca } \\
(\mathrm{g})\end{array}$ & $\begin{array}{l}\text { Número de } \\
\text { tubérculos }\end{array}$ & $\begin{array}{c}\text { Peso dos } \\
\text { tubérculos } \\
\text { (g) }\end{array}$ \\
\hline \multirow[t]{2}{*}{ Achat } & Imersão & 0 & 7 & 20,3 & 23 & 228,1 \\
\hline & & 200 & 5 & 20,6 & 20 & 213,7 \\
\hline \multirow[t]{2}{*}{ Achat } & Injeçâo & 0 & 5 & 19,3 & 18 & 206,7 \\
\hline & & 200 & 3 & 7,7 & 10 & 85,7 \\
\hline \multirow[t]{2}{*}{ Baronesa } & Imersão & 0 & 5 & 20,4 & 15 & 205,7 \\
\hline & & 200 & 5 & 20,6 & 17 & 214,3 \\
\hline \multirow[t]{2}{*}{ Baronesa } & Injeçāo & 0 & 6 & 19,4 & 16 & 201,4 \\
\hline & & 200 & 8 & 16,1 & 15 & 176,0 \\
\hline DMS (5\%) & - & - & 1,6 & 2,6 & 3,2 & 37,5 \\
\hline
\end{tabular}

* Interaçăo cultivar*modo de aplicaçăo*dose significativa pelo teste $\mathrm{F}$ a $1 \%$ de probabilidade.

** Interaçōes cultivar ${ }^{*}$ modo de aplicaçăo e cultivar ${ }^{*}$ dose significativas pelo teste $\mathrm{F}$ a $1 \%$ de probabilidade.

*** Diferença mínima significativa ao nível de $5 \%$ de probalidade.

O paraquat afetou, significativamente, o desenvolvimento da nova geração de plantas nas parcelas da cultivar Achat em que os tubérculos foram injetados com o produto (Tabela 2). A nova geração de plantas ficou debilitada, apresentando menor desenvolvimento da parte aérea e menor potencial para a produção de tubérculos.

Os tubérculos da cultivar Baronesa, apesar da deterioração acentuada da polpa, apresentaram uma boa brotação e com reduções significativas menos acentuadas, no desenvolvimento da nova geração, comparativamente à dose zero.

Todas as plantas oriundas de tubérculos submersos sob diferentes doses de paraquat e aqueles injetados com água apresentaram boas características e desenvolvimento satisfatório.

Esses resultados indicam que quando o paraquat for aplicado sob condições que favoreçam sua penetração ou translocação para o interior do tubérculo, atingindo os vasos e a polpa, pode danificá-lo severamente, prejudicar sua aparência, qualidade de produção e reduzir o desenvolvimento da nova geração de plantas oriundas dos tubérculos contaminados.

\section{2) Metodologia simplificada para detecção de resíduo de paraquat em batata.}

A Figura 1 apresenta os resultados da absorbância das concentrações de soluções padrões de paraquat utilizados para o cálculo de sua curva padrão, expressa pela seguinte equação ajustada : $\mathrm{Y}=0,299849+37,47154 \mathrm{X}$, onde $\mathrm{Y}=$ absorbância em \% e $\mathrm{X}=$ concentração de paraquat em ppm.

Os valores médios de absorbância obtidos na análise de resíduo das amostras de batata contaminadas com paraquat (Tabela 3) foram interpolados à curva padrão do paraquat, estimando assim valores do resíduo recuperado numa
TABELA 3 - Resultados médios da absorbância (\%) e resíduo recuperado (ppm) obtidos pela análise de amostras de batatas contaminadas com paraquat. Dados obtidos da média de 7 repetiçöes de amostras de cascas de $100 \mathrm{~g}$ de batatas.

\begin{tabular}{c|c|c|c}
\hline $\begin{array}{c}\text { Dose simulada } \\
\text { de paraquat } \\
(\mathbf{p p m})\end{array}$ & $\begin{array}{c}\text { Peso das } \\
\text { cascas } \\
(\mathrm{g})\end{array}$ & $\begin{array}{c}\text { Absorbância** } \\
(\%)\end{array}$ & $\begin{array}{c}\text { Resíduo } \\
\text { recuperado** } \\
\text { (ppm) }\end{array}$ \\
\hline 0,00 & 14,87 & $0,00 \mathrm{a}$ & $-0,01$ \\
0,02 & 15,43 & $0,69 \mathrm{a}$ & 0,01 \\
0,06 & 15,93 & $4,59 \mathrm{~b}$ & 0,11 \\
0,10 & 15,33 & $6,28 \mathrm{c}$ & 0,16 \\
0,14 & 16,00 & $7,97 \mathrm{c}$ & 0,20 \\
0,20 & 15,74 & $12,07 \mathrm{~d}$ & 0,31 \\
0,40 & 15,82 & $16,63 \mathrm{e}$ & 0,44 \\
\hline
\end{tabular}

- As medias seguidas pela mesma letra não diferem, significativamente, entre si, a 5\%de probalidade pelo teste de Tukey.

* O resíduo recuperado foi obtido através da interpolaçăo dos dados à curva padrāo do paraquat $(\mathrm{Y}=0,299848+37,47154 \mathrm{X}$, onde $\mathrm{Y}=$ absorbância $\mathrm{em}$ \% e X = concentraçăo de paraquat em ppm).

amplitude de 0 a 0.44 ppm (Figura 1). Nas análises de resíduo das amostras armazenadas até o período de 4 semanas após a simulação do resíduo (contaminação dos tubérculos), não houve diferenças significativas para tempo após a aplicação (Tabela 4). Este resultaddo comprova que o paraquat permanece ativo no interior dos tubérculos por longo tempo, comprometendo assim a qualidade para consumo daquelas batatas contaminadas com o produto. Para efeito de análises 
TABELA 4 - Resultados médios da absorbância (\%) na análise de resíduo das amostras de batata contaminadas com paraquat, durante os períodos de 1 a 4 semanas após a aplicação do herbicida.

\begin{tabular}{c|r|r|r|r|r|c}
\hline \multirow{2}{*}{$\begin{array}{c}\text { Dose simulada de } \\
\text { paraquat (ppm) }\end{array}$} & \multicolumn{5}{|c|}{ Absorbância (\%) Tempo (semanas) } & \multirow{2}{*}{$\begin{array}{c}\text { Resíduo recuperado** } \\
\text { (ppm) }\end{array}$} \\
\cline { 2 - 6 } & $\mathbf{1}$ & $\mathbf{2}$ & $\mathbf{3}$ & $\mathbf{4}$ & Média & 0,01 \\
\hline 0,00 & 0,00 & 0,00 & 0,00 & 0,00 & $0,00 \mathrm{a}$ & 0,01 \\
0,02 & 0,73 & 0,58 & 0,58 & 0,58 & $0,62 \mathrm{a}$ & 0,04 \\
0,06 & 2,08 & 1,93 & 1,62 & 1,92 & $1,89 \mathrm{~b}$ & 0,12 \\
0,10 & 5,56 & 4,42 & 4,74 & 4,42 & $4,78 \mathrm{c}$ & 0,17 \\
0,14 & 6,89 & 6,23 & 7,06 & 6,90 & $6,77 \mathrm{~d}$ & 0,22 \\
0,20 & 9,15 & 7,58 & 8,45 & 8,45 & $8,41 \mathrm{e}$ & 0,27 \\
0,40 & 10,80 & 10,06 & 10,81 & 10,61 & $10,57 \mathrm{f}$ & 0,12 \\
\hline Média & 5,03 & 4,40 & 4,75 & 4,70 & 4,72 & 0 \\
\hline
\end{tabular}

- As médias seguidas pela mesma letra nâo diferem, significativamente, entre si, ao nível de $5 \%$ de probalidade pelo teste de Tuckey.

** Resíduo recuperado calculado através da equaçāo da curva padrāo do paraquat $(\mathrm{Y}=0,299848+37,47154 \mathrm{X}$, onde $\mathrm{Y}=$ absorbåncia em \% e X $=$ concentração de paraquat em ppm).

estatísticas, foram agnupados os tratamentos para tempo, formando um total de 12 repetições, cujo resultado médio de absorbância, para as diferentes doses, foi interpolado à curva padrão e estimado o resíduo recuperado para cada amostra (Tabela 4).

O primeiro experimento (Tabela 3), onde não foi avaliado o efeito do tempo e as análises foram feitas em média 30 minutos após a contaminação dos tubérculos pelo paraquat, apresentou resultados acima do esperado para a maioria das amostras, diferenciando do segundo experimento, o qual apresentou resultados para o resíduo recuperado bem próximo do simulado. Esta diferença ocorreu provavelmente pelo fato de estar trabalhando com valores estimados que já favorecem uma margem de erro e também o fato das análises terem sido feitas no mínimo 1 semana após a contaminação, permitiu a perda do produto para o ambiente ou sua penetração na polpa dos tubérculos, onde não foram feitas análises.

O resíduo recuperado médio calculado pela equação da curva padrão do paraquat, nos dois experimentos, não apresentou diferenças significativas de acordo com as médias de absorbância para as doses 0 e 0,02 ppm, indicando o limite de detecção do método (Tabela 3). Este limite de detecção do método simplificado o torna bastante eficiente, visto que o limite de tolerância do paraquat está em torno de 0,2 ppm (Andrei, 1993; WSSA, 1983). 0 método simplificado aproximou bastante do método analitíco completo, tido como clássico, cujo limite de detecção está em tomo de 0,01 ppm e recuperação acima de $70 \%$ (Zweig, 1967) para amostras de $200 \mathrm{~g}$.

O método analítico requer o uso de corrida das amostras em colunas de resinas para captura das moléculas do paraquat. É um método, geralmente, caro, demorado, necessitando de equipamentos e substâncias químicas especiais. Por outro lado, o método simplificado é barato e rápido, necessitando apenas de $10 \mathrm{ml}$ da solução de ditionito de sódio a $1 \%$ em $\mathrm{NaOH}$ 0,1 N. Para a detecção quantitativa da concentração do resíduo na amostra necessita-se do coloní-metro. Entretanto, pode-se fazer apenas uma análise qualita- tiva da concentração do resíduo de paraquat na amostra através de comparações visuais entre os diferentes graus de cores desenvolvidas nas soluções padrão (item 2.1) e a cor desenvolvida na amostra. Neste caso é dispensável o colorímetro, tomando-se possível a leitura das amostras inclusive no campo. Recomenda-se, neste caso, um kit para o preparo das soluções padrão e leitura das amostras.

\section{AGRADECIMENTOS}

Os autores agradecem ao CNPq pela a bolsa de Iniciação Cientifica concedida ao segundo autor para a realização deste trabalho.

\section{LITERATURA CITADA}

ANDREI, E. (Coord.) Compêndio de defensivos agrícolas: guia prático de produtos fitossanitários para uso agrícola. 4 ed. São Paulo: Andrei Editora, 1993.448 p.

BOOK, O.J. O uso de desfolhantes na produção de batatasemente. In: Tecnologia e produção de batatasemente. Coletânea de artigos técnicos de Agiplan. M.A. 1976, p. 163-172.

BOOK, OJ. Instruções para a cultura da batatinha. 2 ed. Campinas, IAC, 1975.80 p. (IAC. Boletim, 128).

HADERLIE, L.C.; HARDERSON, J.L.; LEINO, P.W.; PETERSEN, PJ.; CALLIHAN, R.H. Chemical dessicattion of potato vines. American Potato Journal, New Jersey, v. 66, n. 2, p. 53-62, 1989.

KLINGMAN, G.C. ; ASHTON, F.M. Weed science: principles and practices. New York: J. Wiley, 1975.431p.

PEREIRA, W. Manejo de plantas daninhas em hortaliças. Brasília: EMBRAPA-CNPH, 1987a, 6p. (EMBRAPACNPH. Circular Técnica, 4). 
PEREIRA, W. Manejo de plantas daninhas e dessecantes. In: REIFSCHNEIDER, F.J.B. ed. Produção de batata. Brasilia: Linha Gráfica, 1987b, p. 67-72.

SOUZA, Z. da S. Prática de dessecação química na produção de batata-semente. Agropecuária Catarinense, Florianópolis, v. 3, n. 1, p. 41-43,1990.

SOUZA, Z. da S.; BONN, V. Dosagens e épocas de aplicação de dessecantes na colheita antecipada da batata-semente. Florianópolis: EMPASC, 1983. 4p. (EMPASC, Pesquisa em Andamento, 17).
SOUZA, Z. da S.; BONIN, V. Efeito dos dessecantes e métodos de desfolha na colheita antecipada. Florianópolis: EMPASC, 1988. 9p (EMPASC, Pesquisa em Andamento).

WEED SCIENCE SOCIETY OF AMERICA. Herbicide handbook of the Weed Science Society of America, 5th, Champaign:, $1983.515 \mathrm{p}$.

ZWEIG, G. Analytical methods for pesticides, plant growth regulators and food additives. New York: Academic Press, 1967. v. 5. p. 475-481. 